\title{
Field Intercomparison of Air Quality Measurements in Switzerland
}

\author{
Jürg Brunner*
}

\begin{abstract}
As part of a national quality assurance programme of the Cercl'Air in cooperation with the Swiss Federal Office for the Environment (FOEN) and the Swiss Federal Office of Metrology (METAS) there have been intercomparisons of air quality monitoring stations of interested institutions in regular intervals since 1988. The former approach, alternating between calibrations with test gases of measuring stations on site and gathering mobile measuring units for additional comparative measurements every second year, had to be modified as mobile measuring stations have become increasingly sparse over the last years. The idea was to find a solution to combine the two types of intercomparison in one campaign. The problem was solved by assembling a mobile reference station for measuring air pollution, with the addition of equipment to provide test gases for the candidate instruments. With this mobile measuring unit, calibration with test gases and comparative measurements could be performed on site at the candidate air pollution monitoring stations. The results of the 2007 intercomparison campaign showed that the achieved quality improvements in air pollution measurements over the last twenty years - decrease of expanded uncertainties in intercomparisons by a factor of 4 to 7 depending on the type of pollutant - could be sustained.
\end{abstract}

Keywords: Air quality monitoring · Calibration · Intercomparison · Quality assurance $\cdot$ Quality control

\section{Introduction}

The Cercl'Air expert group on quality assurance in air pollution monitoring appointed UGZ with the task of carrying out the intercomparison 2007 for air quality measurements. The decreasing number of mobile measuring units had delayed the intercomparison of 2005 as there were no longer enough possible participants. In addition, the mobile units often had to be assembled specially for these occasions and their state did not reflect real life conditions exactly. The expert group for quality assurance in air quality monitoring, Cercl' Air, responsible for the intercomparisons, sought a new approach to the intercomparison of air quality measurements in Switzerland. ${ }^{[1]}$

UGZ, the centre for quality assurance in OSTLUFT, had been performing intercomparisons of air monitoring stations for several years already.[2-7] Our approach consisted of a mobile, motorised refer- ence air pollution monitoring station for comparative measurements on site of the candidate stations. The monitoring station was additionally equipped with the necessary means to perform calibrations with test gases.

\section{Experimental}

The intercomparison took place at 20 air pollution monitoring sites of $16 \mathrm{com}-$ munal, cantonal or national institutions. The reference station, a mobile box cart van, was equipped as listed in the Table. Each Tuesday the reference station was moved and immediately powered up next to a measuring station. The reference instruments for gaseous compounds were calibrated after heating up. On Wednesday calibrations of the candidate instruments with test gases (nitrogen monoxide NO, nitrogen dioxide $\mathrm{NO}_{2}$, sulphur dioxide $\mathrm{SO}_{2}$ and ozone $\mathrm{O}_{3}$ ) and calibration of the sam- ple flow of the high volume PM10 samplers were performed. The calibration gas mixtures were produced on site: $\mathrm{NO}$ and $\mathrm{SO}_{2}$ by dynamic dilution of highly concentrated gas mixtures in pressure bottles, $\mathrm{O}_{3}$ by a transfer calibration standard. The gas calibration mixtures were given in at least two amount fractions, beside zero air, to reference and candidate instrument simultaneously. For the calibration two PTFEtubes were used, one for $\mathrm{NO}$ and $\mathrm{SO}_{2}$, the other for $\mathrm{O}_{3}$. Exhaust tubes led off excess calibration gas and reduced possible pressure influences. During the calibration of the candidate instrument for $\mathrm{SO}_{2}$ the interference of $\mathrm{NO}$ on the signal of $\mathrm{SO}_{2}$ was determined. For $\mathrm{SO}_{2}$ and $\mathrm{O}_{3}$ losses were expected and determined by connecting the calibration tubes to the reference instruments and taken into consideration for the evaluation. $\mathrm{NO}_{2}$ in a low concentrated pressure bottle was supplied to candidate and reference instruments directly. The sample flow of the Digitel high volume samplers

Table. Instrumentation of the reference station

$\begin{array}{llll}\text { Instrumentation } & \text { Reference Instrument Type } & \text { Serial Nr. } & \text { Year } \\ \text { Nitrogen oxides } & \text { Horiba APNA 370 } & \text { G0300LOL } & 2006 \\ \text { Ozone } & \text { Horiba APOA 370 } & \text { G0100U75 } & 2006 \\ \text { Sulphur dioxide } & \text { Horiba APSA 370 } & \text { EHPT0000 } & 2006 \\ \text { Particulate Matter PM10 (gravimetric) } & \text { Digitel DHA-80 } & 322-N & 1997 \\ \text { Ozone calibration unit } & \text { Horiba APOA 360CE OZGU } & 004004 & 2000 \\ \text { Dynamic dilution } & \text { Bronkhorst E-7402 } & \text { M4208162A } & 2004\end{array}$

${ }^{\star}$ Correspondence: J. Brunner

Umwelt- und Gesundheitsschutz Zürich (UGZ) Leistungszentrum Qualitätssicherung OSTLUFT

Walchestrasse 31

$\mathrm{CH}-8021$ Zürich

Tel.: +41444122832

Fax: +41442709453

E-Mail: juerg.brunner@zuerich.ch 
for particulate matter PM10 was calibrated by means of a turbine flow meter. After the calibration simultaneous measurements of outdoor air were performed until the next transfer to a monitoring site.

\section{Metrological Traceability}

Traceability means that the result of a measurement can be related to a measurement standard, national or international, and that these relations are documented. Measuring instruments have to be calibrated by using standards, which themselves are traceable. The means of calibration for the intercomparison could be retraced directly or indirectly to the corresponding national measurement standard in an unbroken metrological traceability chain (Fig. 1).

\section{Evaluation}

The intercomparison factors for NO, $\mathrm{SO}_{2}$ and $\mathrm{O}_{3}$ were calculated as slopes of a linear regression analysis, forced through the origin, of the zero-corrected calibration signals of the candidate instrument and the corresponding calibration gas amount fraction. It gives a recovery factor for the calibration gas mixtures used (Fig. 2).

As two out of the three pressure bottles used for the calibration of $\mathrm{NO}_{2}$ showed an increasing amount fraction during the calibration tests, the intercomparison factor had to be calculated as the fraction of the zero-corrected data of the candidate instrument to the zero-corrected data of the reference instrument. For all gaseous compounds the expanded uncertainty in the intercomparisons was determined.

The evaluation of the comparative measurements on outdoor air was performed by linear regression analysis of half hour means for the gaseous components and daily means for the measurements of particulate matter PM10 with the Digitel high volume sampler.

\section{Results}

\subsection{Calibration with Test Gas Mixtures}

The intercomparison factors for the gaseous compounds and for the sample flow of the particulate instruments (Fig. 3) show a good accordance of the candidate and the reference instruments. The distinctively high zero values for $\mathrm{NO}_{2}$ in the measurement of zero air were measured by all instruments of the same type and producer, probably due to an interference of a component contained in the zero air. Low intercomparison factors for $\mathrm{NO}_{2}$ may indi-

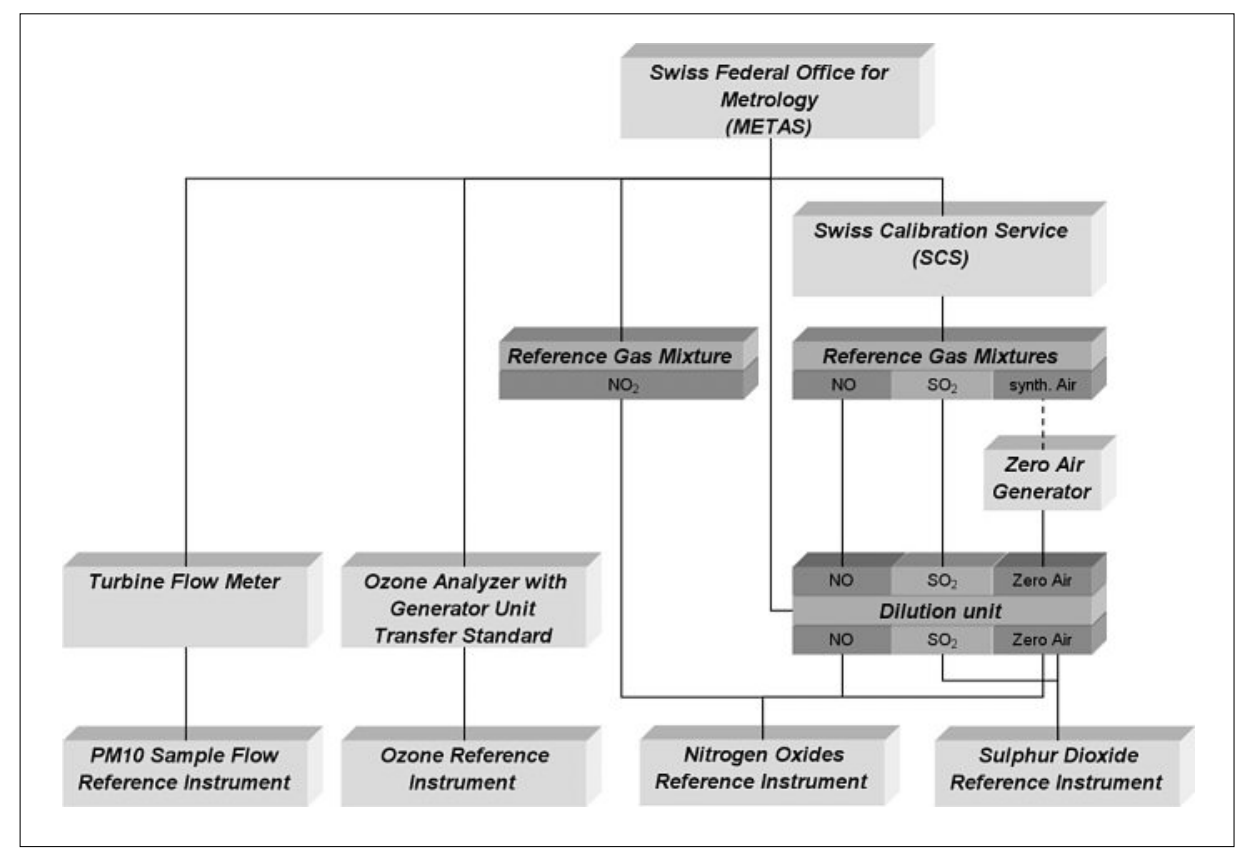

Fig. 1. Traceability of the reference measuring instruments used for the intercomparison 2007 to national measurement standards.

cate insufficient converter efficiency in the catalytic conversion of $\mathrm{NO}_{2}$ to $\mathrm{NO}$ of the chemiluminescence monitors.

Unfortunately, most of the participating institutions have only limited knowledge of the uncertainty of their measurements. The indicated expanded uncertainties take into account only the uncertainty contributions of calibration means and the linear regression analysis.

\subsection{Comparative Measurements on Outdoor Air}

In addition to the calibration settings of the measuring instruments the results of outdoor air pollution measurements (Fig. 4) depend on the sample system used. Residence time and cleanliness, small leaks and solenoid valves used in the sample path may influence the measurements. $\mathrm{O}_{3}$ reacts with $\mathrm{NO}$ in forming $\mathrm{NO}_{2}$ during resi-

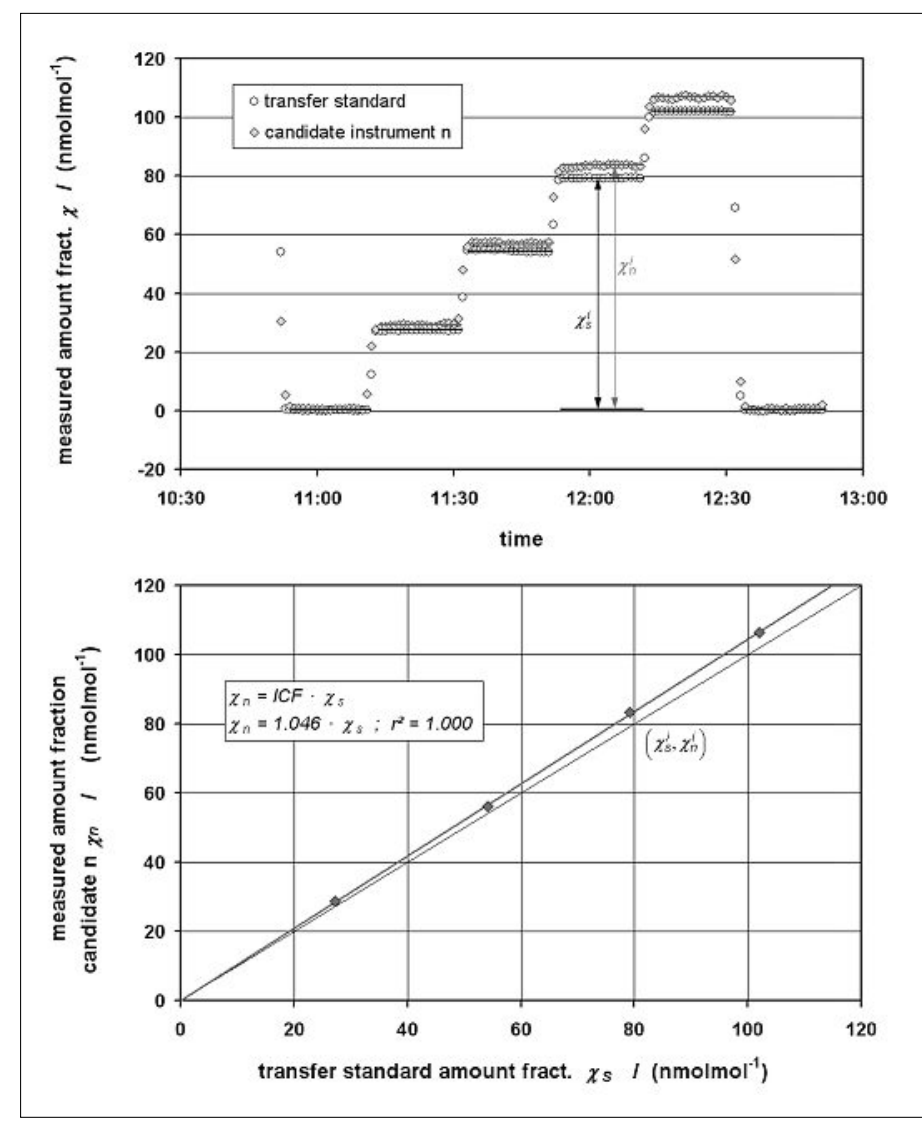

Fig. 2. Example for the calculation of an intercomparison factor (ICF) for ozone. 
Nitrogen monoxide NO

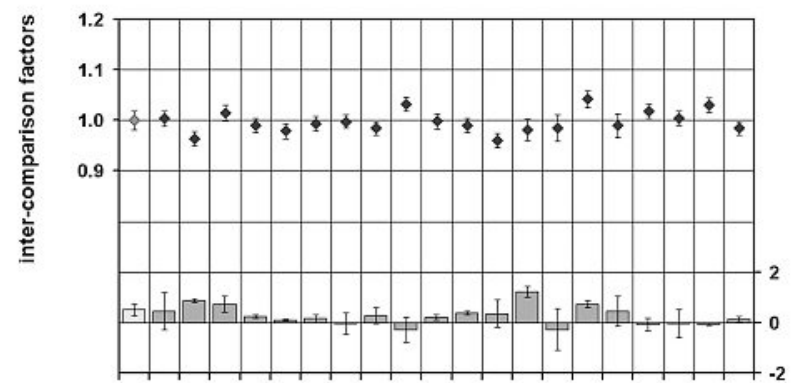

Nitrogen dioxide $\mathrm{NO}_{2}$

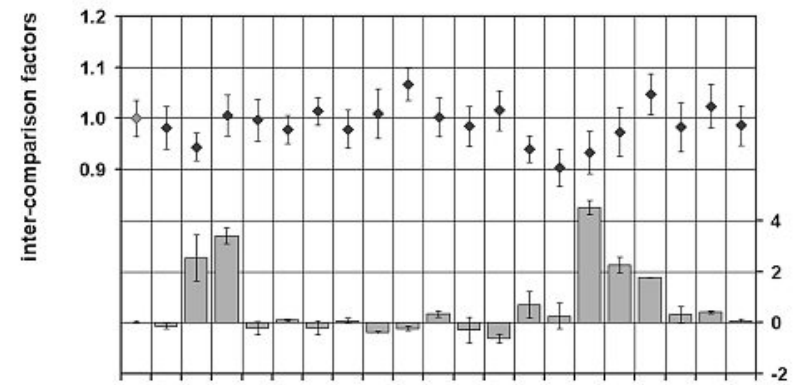

Ozone $\mathrm{O}_{3}$

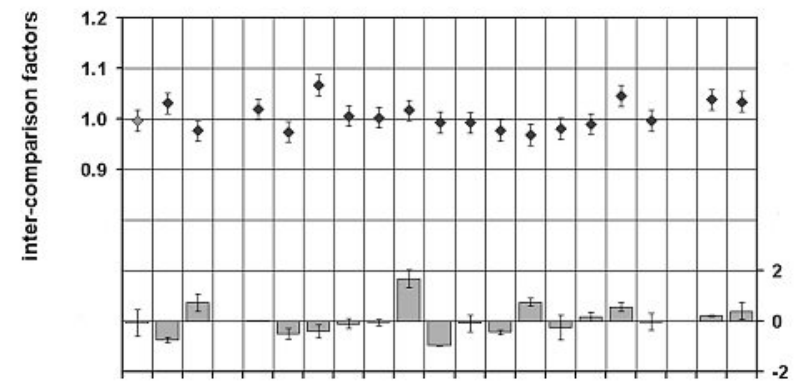

Sulphur dioxide $\mathrm{SO}_{2}$

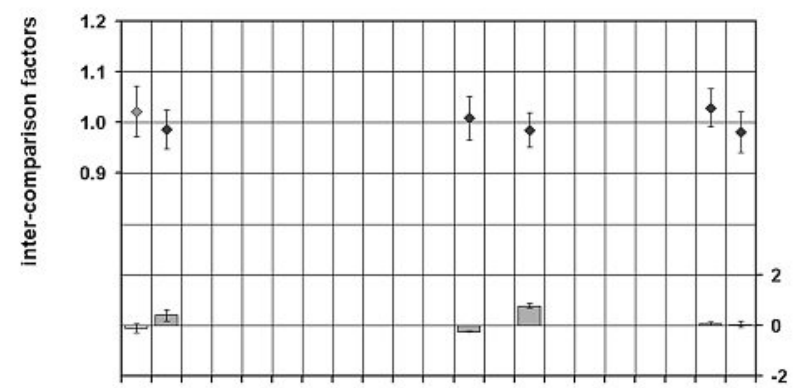

Sample Flow Digitel DHA80

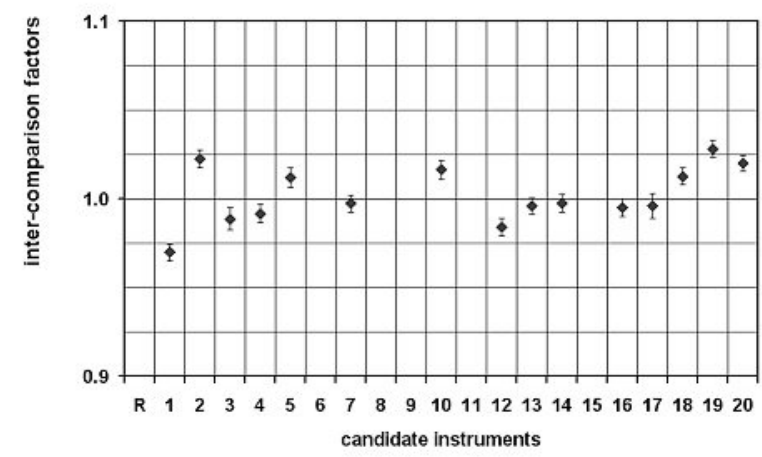

Fig. 3. Intercomparison factors - and slopes with corresponding uncertainties for gaseous compounds and sample flow of the high volume samplers for PM10 (R: Reference).
Nitrogen monoxide NO

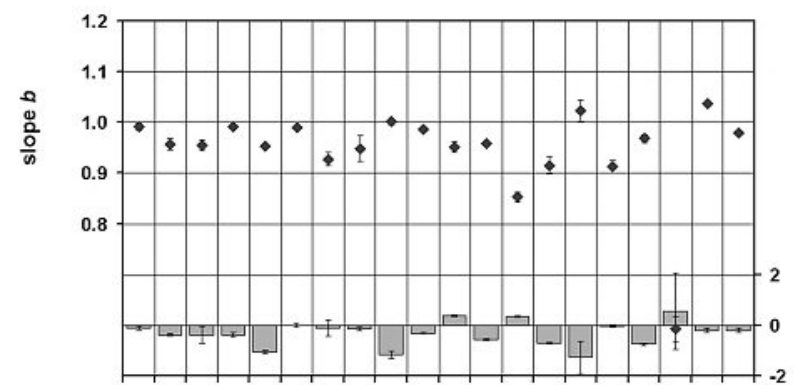

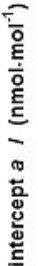

Nitrogen dioxide $\mathrm{NO}_{2}$

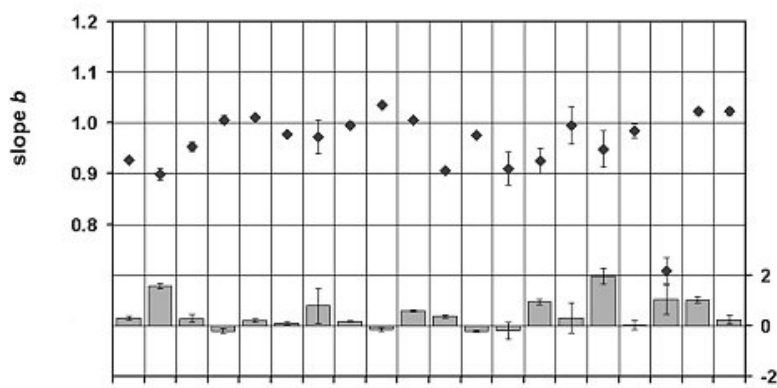

Ozone $\mathrm{O}_{3}$

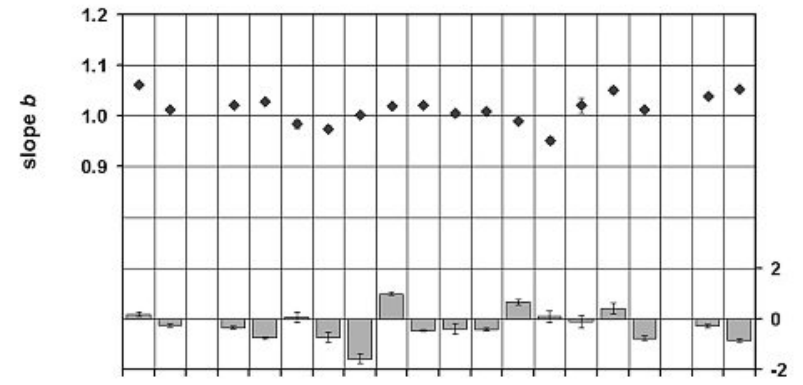

Eั

Sulphur dioxide $\mathrm{SO}_{2}$

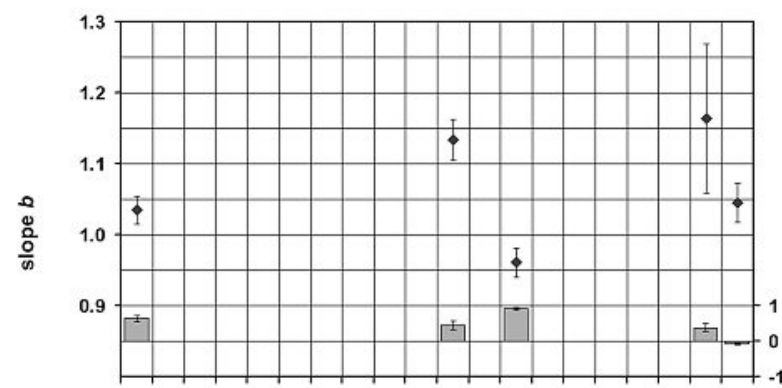



Particulate Matter PM10

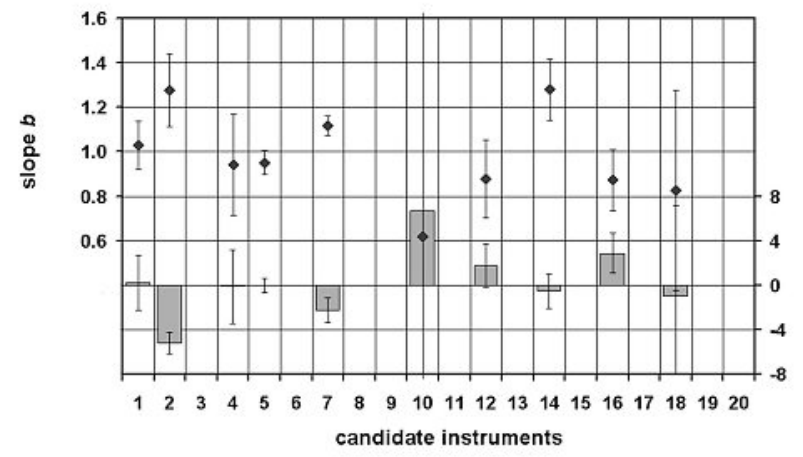

Fig. 4. Slope - and intercept a with corresponding uncertainties of the comparative measurements on outdoor air. 
dence in the sampling system. Most of the candidate measurement data show more or less pronounced evidence of chemical reactions in the sampling system, lower recoveries for $\mathrm{NO}$, negative intercepts in the case of $\mathrm{O}_{3}$ and $\mathrm{NO}$ and positive intercepts in the case of $\mathrm{NO}_{2}$. An extreme case is the measured data for nitrogen oxides for candidate 18 , where on the basis of the comparative measurements, a non-working bypass pump could be identified as the reason for the deviation.

The above-average uncertainty of the $\mathrm{SO}_{2}$ measurements of candidate 19 indicates a technical problem with the instruments or a possible interference of nonidentified compounds.

The interpretation of the comparative measurements for particulate matter PM10 is more difficult. Although the calibration of the sample flow showed good results for all participants, the variance in the data of some institutions is clearly too high. Candidate 10 had a malfunction of the high volume sampler, the remaining three values were very close and the regression analysis gives an inconsistent result. As gravimetric determinations of dust samples on a filter should not be any problem, the reason lies most probably in the conditioning of the filters before gravimetric analysis of sampled particulates. Another, though less probable, reason might be leaking filter rings during sampling.

As for the calibration experiments the indicated expanded uncertainties contain only the uncertainties of the parameters of the linear regression analysis.

\section{Conclusion}

The evolution of expanded uncertainties in intercomparisons since 1988 (Fig. 5) shows a clear decrease for all gaseous compounds. ${ }^{[8-13]}$ This improvement has a direct impact on the comparability of air pollution measurements and has several causes:

- Increasing efforts to retrace measuring instruments and calibration means to national standards (certified gas mixtures, METAS campaigns for the calibration of $\mathrm{O}_{3}$-transfer standards and other calibration means);

- Improved fabrication techniques in the production of bottled high-pressure gas mixtures;

- Improved dilution techniques for highly concentrated gas mixtures;

- Several new generations of measuring instruments with better characteristics developed in the last twenty years.

Nevertheless the calibration of the measuring instruments and the traceability to national standards is just one aspect. As the results of the comparative measure-

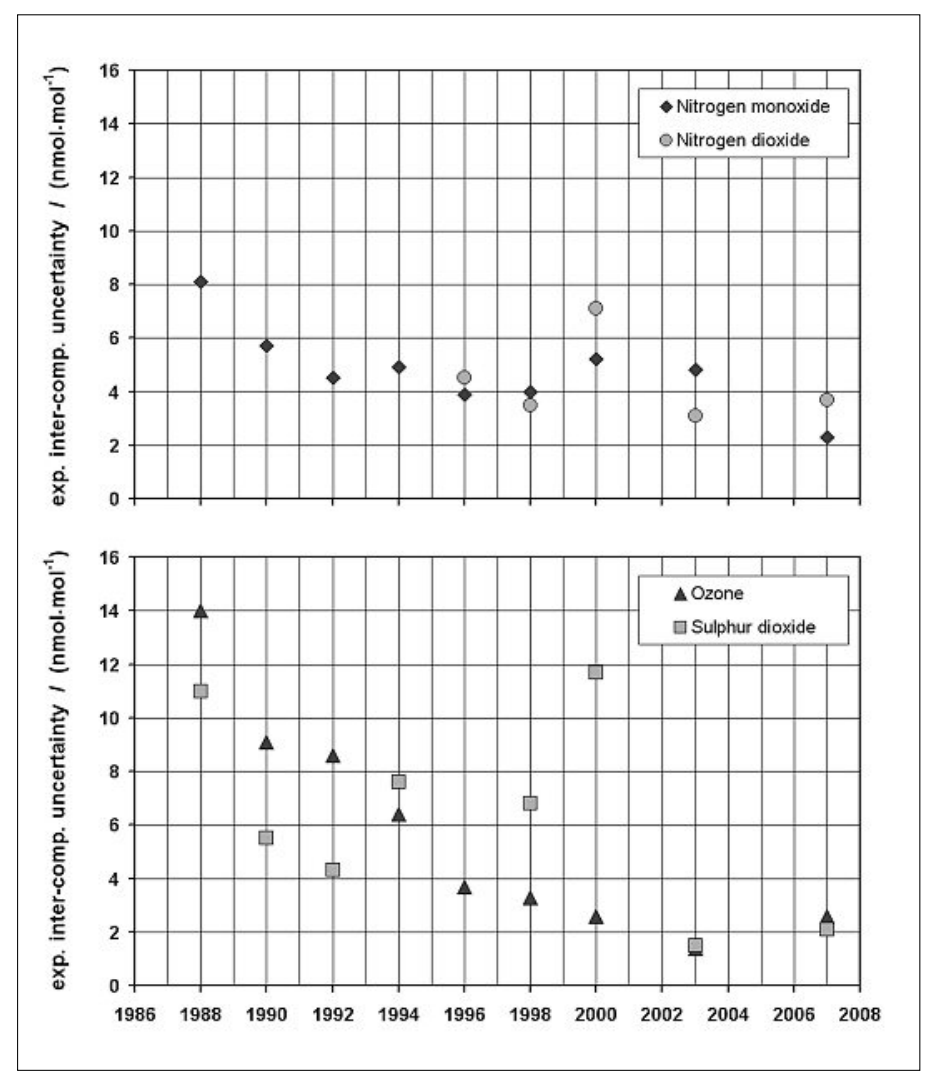

Fig. 5. Evolution of expanded uncertainties for the amount fractions of gaseous $\mathrm{NO}$ $\mathrm{NO}_{2}$ and $\mathrm{O}_{3}, \mathrm{SO}_{2}$ in intercomparisons since 1988.

ments of the actual intercomparison indicate, other experimental factors influence the results of air pollution measurements, especially inappropriate or even faulty sampling systems. In this area, there seems to be future potential for optimisation in measuring gaseous air pollutants.

For future intercomparisons more stable calibration means, such as permeation tubes or gas phase titration, may be better options, in place of high-pressure bottles with low amount fractions of $\mathrm{NO}_{2}$.

Another important conclusion to arise from this intercomparison campaign is the limited knowledge of the uncertainty of their measured data by almost all of the participants. For future intercomparisons and interpretation of the results, it is imperative to have a better knowledge about uncertainty contributions originating from the candidate instruments.

\section{Abbreviations}

Cercl'Air Swiss Society of Air Hygiene FOEN Swiss Federal Office for the Environment (FOEN)

METAS Swiss Federal Office of Metrology

OSTLUFT Association of the eastern cantons of Switzerland and the Principality of Liechtenstein for Air Pollution Monitoring Swiss Calibration Service Umwelt- und Gesundheitsschutz Zürich (UGZ)

(Environment and Health Protection of the City of Zurich)
[1] Cercl'Air, Qualitätssicherung von Immissionsmessungen für Gase und Partikel in der Schweiz - Empfehlung, Empfehlung Nr. 13, Herisau, 2009.

[2] J. Brunner, 'OSTLUFT/UGZ, OSTLUFT Ringkalibration und Vergleichsmessungen 2001', Bericht Nr. QS2001_001, Zürich, 2001.

[3] J. Brunner, 'OSTLUFT/UGZ, OSTLUFT Ringkalibration und Vergleichsmessungen 2002', Bericht Nr. QS2002_002, Zürich, 2002.

[4] J. Brunner, 'OSTLUFT/UGZ, OSTLUFT Ringkalibration und Vergleichsmessungen 2003', Bericht Nr. QS2004_001, Zürich, 2004.

[5] J. Brunner, 'OSTLUFT/UGZ, OSTLUFT Ringkalibration und Vergleichsmessungen 2004', Bericht Nr. QS2004_002, Zürich, 2004.

[6] J. Brunner, 'OSTLUFT/UGZ, OSTLUFT Ringkalibration und Vergleichsmessungen 2005', Bericht Nr. QS2005_001, Zürich, 2005.

[7] J. Brunner, 'OSTLUFT/UGZ, OSTLUFT Ringkalibration und Vergleichsmessungen 2006', Bericht Nr. QS2006_001, Zürich, 2006.

[8] INFRAS/BUWAL, 'Ringversuche und Ringkalibrationen als Mittel der Qualitätssicherung', 1993.

[9] Ökoscience Lufthygiene AG/BUWAL, 'Bericht Ringkontrolle 1994 in der Schweiz', Bericht Nr. 104472, Zürich/Chur, 1995.

[10] INFRAS/BUWAL, 'Ringversuch Immissionsmessungen 1996 in Bern, Zürich', 1997.

[11] Ökoscience Lufthygiene AG/BUWAL, 'Ringkontrolle 1998 in der Schweiz, Zürich/Brugg/ Chur', 1999.

[12] INFRAS/BUWAL, 'Ringversuch Immissionsmessungen 2000 in Basel, Zürich/ Bern', 2000.

[13] Kull Instruments/Cercl'Air/BAFU, 'Ringkontrolle 2003 in der Schweiz, Oftringen', 2004. 